\title{
PERAN PEMERINTAH KABUPATEN SIMEULUE DALAM PEMBERDAYAAN AIR BERSIH DAN SANITASI GUNA MENDORONG PENGEMBANGAN KAPASITAS DAERAH SERTA PENYEDIAAN PELAYANAN AIR MINUM DAN PENYEHATAN LINGKUNGAN UNTUK MEMENUHI TARGET UNIVERSAL ACCES 100\% MDGS PROGRAM TINGKAT NASIONAL
}

\author{
Alimas Jonsa dan Irwan Suharmi \\ Desen Fakultas Ilmu Sosial Dan Ilmu Politik, Universitas Teuku Umar \\ alimasjonsa@gmail.com \\ Dosen Fakultas Ekonomi Dan Bisnis, Univeristas Teuku Umar \\ irwan.suharmi@gmail.com
}

\begin{abstract}
The role of the government in empowering the development community in the Simeulue Islands Regional Water Supply and Environmental Sanitation Action Plan (RAD) will not succeed if it is not balanced with a public awareness program that is an effort to reduce, poor culture by way of remind, convince and injections to the community. To be trying to bounce do the hard work to get used to shame the poor receive aid as well as mental block change. The program targets AMPL activities in sequential order from the district level, the District, the Village (Village / Agencies) reached the target group. This is done through a mechanism in the development plan Deliberation annual planning and budgeting cycle of the area. The purpose of RAD AMPL needs to be supported by the role of the government by prioritizing synergic relations between elements of government, the private sector and civil society and involving the community itself based on the principles of Vision Strategy, by means of transparency, participation, and responsibility, by prioritizing community interests. By looking at the conditions of the community above, the government needs to do a social empowerment. Thus the RAD AMPL requires the support and participation of all development actors from the government, DPRD, universities, organizations and non-governmental organizations, private and international institutions. The involvement of all development actors are expected to encourage the establishment of a common point of view, the agreement and synergy in the efforts to Accelerate Achievement of Universal Access target of $100 \%$.
\end{abstract}

Keywords: Role, Government, Empowerment, Clean Water. 


\section{PENDAHULUAN}

Air minum dan Sanitasi yang merupakan salah satu kebutuhan dasar bagi keberlangsungan kehidupan manusia. Berdasarkan Undang-Undang No. 23 Tahun 2014 Tentang Pemerintahan Daerah, pelayanan air minum dan sanitasi telah urusan wajib Pemerintah Daerah. Untuk mendukung kapasitas daerah dalam menyediakan layanan air minum dan sanitasi yang memenuhi Standar Pelayanan Minimum (SPM), Pemerintah Pusat berperan dalam menyediakan dukungan finansial baik untuk investasi fisik dalam bentuk sarana dan prasarana, maupun investasi non-fisik dalam bentuk manajemen, dukungan teknis dan pengembangan kapasitas dengan sharing Pemerintah Daerah dan semua pihak untuk bersama berkontribusi termasuk melibatkan masyarakat dengan pola berbasis masyarakat guna pencapaian sasaran nasional dan pengendalian pelaksanaan untuk perwujudan standar pelayanan minimal.

Berdasarkan data Dinas Kesehatan Kabupaten Simeulue tahun 2016, cakupan layanan air minum di Kabupaten Simeulue baru mencapai 51.08\% untuk wilayah perdesaan dan $53.46 \%$ Cakupan wilayah perkotaan telah terlayani dengan baik, sedangkan cakupan akses sanitasi sudah mencapai $31.86 \%$, untuk wilayah perdesaan dan $57.31 \%$ cakupan wilayah perkotaan. Adapun sesuai RPJMN Tahun 2015-2019 diharapkan cakupan ini dapat meningkat menjadi $100 \%$ untuk air minum dan $100 \%$ untuk sanitasi.

Sehubungan dengan hal ini diperlukan suatu perencanaan program air minum dan sanitasi yang akan menjadi acuan seluruh pihak yang berkepentingan. Sumber air minum yang layak meliputi air minum perpipaan dan air minum non-perpipaan terlindung yang berasal dari sumber air berkualitas dan berjarak sama dengan atau lebih dari 10 meter dari tempat pembuangan kotoran dan/atau terlindung dari kontaminasi lainnya. Sumber air minum layak meliputi air leding, keran umum, sumur bor atau pompa, sumur terlindung dan mata air terlindung, serta air hujan;

Sumber air minum tak layak didefinisikan sebagai sumber air di mana jarak antara sumber air dan tempat pembuangan kotoran kurang dari 10 meter dan/atau tidak terlindung dari kontaminasi lainnya. Sumber tersebut antara lain mencakup sumur galian yang tak terlindung, mata air tak terlindung, air yang diangkut dengan tangki/drum kecil, dan air permukaan dari sungai, danau, kolam, dan saluran irigasi/drainase;

Fasilitas sanitasi yang layak didefinisikan sebagai sarana yang aman, higienis, dan nyaman, yang dapat menjauhkan pengguna dan lingkungan di sekitarnya dari kontak dengan kotoran manusia.

Fasilitas sanitasi yang layak mencakup kloset dengan leher angsa, toilet guyur (flush toilet) yang terhubung dengan sistem pipa saluran pembuangan atau tangki septik, termasuk jamban cemplung (pit latrine) terlindung dengan segel slab dan ventilasi; serta toilet kompos.

\section{Kerangka Konsep}

Partisipasi Pemerintah Dalam Pengelolaan Air Bersih.

Dalam Tujuan Pembangunan Milenium, definisi operasional akses air minum layak adalah yang menggunakan sumber air minum layak seperti sambungan air minum rumah tangga, lubang bor, sumur gali yang terlindungi, mata air terlindung, tampungan air hujan. Sedangkan definisi operasional akses sanitasi layak adalah yang menggunakan sanitasi dasar seperti toilet guyur/toilet siram guyur atau jamban, pipa saluran pembuangan, tangki septic atau jamban lubang, jamban cemplung dengan ventilasi yang baik, jamban cemplung dengan segel slab atau toilet/jamban kompos.

Akses aman terhadap air minum terdiri dari Jaringan Perpipaan dan Bukan Jaringan Perpipaan (BJP). Sistem Penyediaan Air Minum (SPAM) Bukan Jaringan Perpipaan adalah sebagaimana diatur dalam Peraturan Pemerintah Nomor : 122 Tahun 2015 Tentang Sistem Penyediaan Air Minum. Jenis SPAM meliputi SPAM Jaringan Perpipaan dan SPAM Bukan Jaringan Perpipaan. 
SPAM Jaringan Perpipaan meliputi : Unit Air Baku, Unit Produksi, Unit Distribusi Unit Pelayanan. SPAM Jaringan Bukan Perpipaan meliputi : Sumur Dangkal, Sumur Pompa, Bak Penampungan Air Hujan, Terminal Air, Bangunan Penangkap Mata Air.

a. Peningkatan cakupan dan kualitas pelayanan air minum dan sanitasi: Mengidentifikasi sumber-sumber air baku untuk peningkatan cakupan layanan, Penambahan zat koagulan (tawas, kaporit) untuk meningkatkan kualitas air, Melakukan pengendalian daerah tangkapan air (reboisasi), Pemicuan untuk kepemilikan jamban dan peningkatan PHBS.

b. Pengembangan pendanaan untuk penyelenggaran SPAM dan SPAL: Mengalokasikan dana dari APBD Kabupaten Simeulue, Provinsi dan Pusat, Melibatkan partispasi masyarakat dan dunia usaha (lembaga donor).

c. Pengembangan kelembagaan, peraturan dan perundang-undangan: Penguatan kelembagaan BPSPAMS, Penguatan dan peningkatan pemahaman terhadap Rencana Pembangunan Jangka Menengah (RPJM ) Kabupaten Simeulue tentang.

d. Peningkatan penyediaan air baku secara berkelanjutan: Mengidentifikasi sumbersumber air baku untuk peningkatan cakupan layanan, Melakukan pengendalian daerah tangkapan air (reboisasi),Melakukan konservasi disekitar sumber air baku.

e. Peningkatan peran dan kemitraan pemerintah, dunia usaha dan masyarakat: Melakukan advokasi kepada dunia usaha dan masyarakat, Meningkatkan koordinasi antar lembaga terkait.

\section{Arah Kebijakan}

Berdasarkan tujuan dan sasaran peningkatan pelayanan AMPL Kabupaten Simeulue, arah kebijakan dan strategi yang akan dilakukan adalah sebagai berikut: Memprioritaskan perluasan cakupan pelayanan PDAM pada kawasan perkotaan dan kawasan pengembangan pelayanan PDAM (kawasan potensial PDAM)., Menerapkan pendekatan berbasis masyarakat untuk perluasan cakupan akses air minum yang layak dan berkelanjutan di kawasan perdesaan dan kawasan yang tidak terjangkau pelayanan PDAM., Menggalang kerjasama pendanaan dengan dunia usaha bagi perluasan akses air minum dan sanitasi pada kawasan-kawasan pariwisata., Menggalakkan program STBM bagi Kelurahan/Desa dengan tingkat cakupan akses sanitasi rendah di bawah rata-rata kabupaten., Menggalakkan kampanye PHBS melalui mobilisasi tenaga promosi kesehatan, tokoh masyarakat, kelompok masyarakat, dan media massa., Meningkatkan pengelolaan dan pengawasan sumberdaya air untuk menjamin kuantitas, kualitas, dan kontinuitas pasokan air baku., Meningkatkan koordinasi lintas program dan lintas pelaku pembangunan air minum dan sanitasi melalui penguatan peran Bappeda Kabupaten Simeulue., Meningkatkan alokasi APBD untuk memenuhi minimal 40\% kebutuhan investasi AMPL Kabupaten Simeulue dalam rangka pencapaian target 7C MDGs dan Universal Akses. Adapun sisanya (60\%) diupayakan melalui pendanaan APBD provinsi, APBN, CSR, dunia usaha, dan lembaga keuangan atau perbankan.

\section{METODE PENELITIAN}

\section{Lokasi Dan Waktu Pelaksanaan Penelitian}

Lokasi penelitian dilaksanakan di Kabupaten Simeulue. Penelitian ini dilakukan melalui pendekatan kualitatif dengan metode survey (descriptive exploratory study). Survey dalam penelitian ini dilakukan terhadap semua intansi pemerintah yang berhubungan langsung dengan liding sektor PDAM Tirta Fulawan Pemerintah di Kabupaten Simeulue. Model survey ini disebut survey lengkap atau sensus. Secara normatif, survey digunakan untuk memaparkan data dari objek penelitian, menginterpretasikan dan menganalisisnya secara sistematis. Waktu pelaksanaan penelitian dimulai pada Bulan April sampai dengan Oktober 2018. 


\section{Jenis Dan Sumber Data}

Penelitian ini merupakan suatu studi kasus dengan jenis data primer dan sekunder. Dalam penelitian ini data primer adalah jawaban langsung dari informan yang berkaitan dengan penelitian. Data primer bertujuan untuk memenuhi kebutuhan dalam penelitian. Data primer ini seperti dikatakan Bagong Suyanto dan Sutinah (2008, h. 55) bahwa "data primer yaitu data yang diperoleh langsung dari obyek yang akan diteliti (responden). Pengumpulan data primer dengan menggunakan instrumen penelitian, yaitu interview guide dan wawancara tidak berstruktur. Sedangkan menurut Bungin (2008, h. 122): "Data sekunder adalah data yang diperoleh dari sumber kedua atau sumber sekunder dari data yang kita butuhkan misalnya melalui dokumen". Data sekunder itu merupakan data yang diperoleh oleh peneliti dari sumber-sumber yang telah ada. Diketahui bahwa sebelum penelitian dilakukan oleh peneliti, data sekunder memang sudah tersedia, data ini diperoleh dari studi kepustakaan, dokumen, koran, internet yang berkaitan dengan kajian penelitian. Dalam penelitian ini yang akan dijadikan sumber data sekunder adalah data-data dari beberapa literatur seperti laporan penelitian, jurnal dan buku-buku yang berkaitan dengan pelaksanaan Keterbukaan Informasi Publik.

Sementara untuk penelitian yang dilakukan adalah Metode Penelitian Survey dengan mengikuti beberapa langkah-langkah sebagaimana yang dikemukakan oleh Singarimbun (1995, h. 3), sebagai berikut : Merumuskan masalah penelitian dan menentukan tujuan survey,. Menentukan konsep dan hipotesa serta menggali kepustakaan. Adakalanya hipotesa tidak diperlukan, misalnya pada penelitian operasional., Pengambilan sampel., Pembuatan kuesioner., Pekerjaan lapangan, termasuk memilih dan melatih pewawancara., Pengolahan data.,Analisa dan pelaporan.

\section{Metode Dan Pengumpulan Data}

Proses penelitian Pada Instasi Pemerintah dan swasta ini akan dibagi dalam dua tahap, yaitu :

1. Tahap Pertama; disebut dengan self assessment (kajian mandiri) oleh intansi pemerintah yang berhubungan langsung dengan program air minum dan sanitasi . Pada tahap ini, peneliti akan mengirimkan kuesioner yang harus diisi oleh intansi pemerintah, dan selanjutnya dilakukan verifikasi terhadap dokumen yang dikembalikan.

2. Tahap Kedua; disebut dengan kunjungan lapangan. Pada tahap ini, peneliti akan menetapkan sampel penelitian terpilih sesuai dengan penetapan pemeringkatan awal dan dipilih $(10 \%-15 \%)$ yang masuk nominasi.

\section{HASIL DAN PEMBAHASAN}

\section{Tantangan Pengembangan Air Minum Dan Sanitasi Di Kabupaten Simeulue.}

Pemerintah Kabupaten Simeulue dalam analisis hasil dari beberapa data dokumen terkait peneliti lakukan peran pemerintah dalam pemberdayaan air bersih dan sanitasi guna mendorong pengembangan kapasitas daerah serta penyedian air minum akses yang merata dibutuhkan sangat investasi dalam hal finansial.

Perkiraan kebutuhan investasi pelayanan AMPL daerah bertujuan untuk mengetahui perkiraan investasi yang akan diperlukan dalam rangka pencapaian target RPJMN. Dengan adanya perkiraan ini, diharapkan pemerintah daerah dapat mempersiapkan strategi pendanaan dan pilihan program/kegiatan yang lebih efektif dan efisien dalam mencapai kinerja yang ditargetkan.

Angka hasil perkiraan investasi merupakan gambaran biaya yang diperlukan daerah sebagai pertimbangan dalam peningkatan alokasi anggaran APBD untuk AMPL dan pertimbangan dalam perumusan program dan kegiatan yang diusulkan untuk didanai APBD provinsi dan APBN, juga dunia usaha/perbankan, dan masyarakat. 
Upaya pencapaian target kinerja AMPL Kabupaten Simeulue sampai dengan tahun 2021 sebagaimana disebutkan diatas perlu didukung dengan komitmen penuh dari berbagai pihak yang terkait, baik dari segi sumber daya manusia maupun pendanaan. Sehubungan dengan itu, diperlukan perhitungan kebutuhan investasi yang matang guna menyiapkan strategi investasi dan pendanaan program AMPL. Sebagai acuan awal, perkiraan kebutuhan investasi dalam rangka pencapaian target kinerja AMPL Kabupaten Simeulue tahun 2021 adalah sebagai berikut :

Tambahan akses sampai dengan 2021 dihitung berdasarkan target kabupaten, baik pada air minum dan sanitasi. Berdasarkan tambahan akses tersebut, investasi air minum dihitung dengan menggunakan pendekatan kelembagaan, pendekatan pemberdayaan masyarakat, dan kombinasi antara pendekatan kelembagaan dan pemberdayaan masyarakat. Penerapan pendekatan penghitungan investasi air minum didasarkan pada hasil pemetaan atas besar tambahan akses yang dapat dipenuhi dengan pendekatan kelembagaan, pemberdayaan masyarakat, dan kombinasi keduanya.

\section{Tabel 1.}

Analisis Kebutuhan Investasi Pelayanan Air Minum dan Sanitasi Kab. Simeulue

\begin{tabular}{|c|c|c|c|c|c|c|}
\hline No. & Indikator & \begin{tabular}{c|} 
Kondisi \\
saat ini \\
Tahun \\
2017
\end{tabular} & $\begin{array}{l}\text { Kondisi } \\
\text { tahun } \\
2021\end{array}$ & $\begin{array}{c}\text { Tambahan } \\
\text { cakupan } \\
\text { pelayanan }\end{array}$ & $\begin{array}{c}\text { Biaya investasi } \\
\text { per orang }(\mathrm{Rp},-)\end{array}$ & $\begin{array}{c}\text { Kebutuhan } \\
\text { investasi s.d tahun } \\
2021(\mathrm{Rp},-)\end{array}$ \\
\hline \multirow[t]{3}{*}{1} & \multicolumn{6}{|c|}{ Jumlah penduduk yang dilayani Air Minum } \\
\hline & - Perdesaan & 28.369 & 62,017 & & $1.280 .000 / \mathrm{jw}$ & $43,071,102,407$ \\
\hline & - Perkotaan & 11.641 & 32,339 & & $1.280 .000 / \mathrm{jw}$ & $26,493,699,133$ \\
\hline \multirow[t]{3}{*}{2} & \multicolumn{5}{|c|}{ Persentase cakupan penduduk yang dilayani Air Minum } & \\
\hline & - Perdesaan & $51.08 \%$ & $100 \%$ & & & \\
\hline & - Perkotaan & $53.46 \%$ & $100 \%$ & & & \\
\hline & \multicolumn{5}{|c|}{ Total Kebutuhan Investasi Air Bersih } & $69,564,801,540$ \\
\hline \multirow[t]{3}{*}{3} & \multicolumn{5}{|c|}{ Jumlah penduduk yang dilayani sanitasi Air Sanitasi } & \\
\hline & - Perdesaan & 17.697 & 62,017 & & & \\
\hline & - Perkotaan & 12.48 & 32,339 & & & \\
\hline \multirow[t]{6}{*}{4} & \multicolumn{5}{|c|}{ Persentase cakupan penduduk yang dilayani Sanitasi } & \\
\hline & - Perdesaan & $31.86 \%$ & $100 \%$ & & & $8,864,049,450$ \\
\hline & - Perkotaan & $57.31 \%$ & $100 \%$ & & & $3,971,711,130$ \\
\hline & \multicolumn{5}{|c|}{ Total Kebutuhan Investasi Sanitasi } & $12,835,760,580$ \\
\hline & & & & & & \\
\hline & \multicolumn{5}{|c|}{ Total kebutuhan Air Bersih dan Sanitasi } & $82,400,562,120$ \\
\hline
\end{tabular}

Sumber : Dokumen Hasil Analisa data Bappeda Kabupaten Simeulue Tahun 2017.

Berdasarkan capaian kinerja AMPL Kabupaten Simeulue sampai dengan tahun 2017, target pencapaian bidang air minum dan sanitasi, padaakhir 2021 Kabupaten Simeulue diharapkan mampu mencapai kondisi $100 \%$ penduduk memiliki akses air minum dan sanita silayak. Untuk mencapai kondisi tersebut, diperkirakan kebutuhan investasi selama 2017-2021 untuk air minum dalah Rp.69.564.801.540,- dan untuk sanitasi adalah Rp. 12.835.760.580,Dengan demikian kebutuhan investasi air minum dan sanitasi selama 2017-2021 mencapai Rp.82.400.562.120,- atau Rp.16.480.1123.424,- pertahun.

Dengan rata-rata realisasi APBD untuk AMPL di Kabupaten Simeulue per tahun, sangat kecil maka hasil perhitungan investasi air minum dan sanitasi Kabupaten Simeulue menunjukkan perlunya: Anggaran AMPL difokuskan keperkotaan dan perdesaan, Meningkatkan alokasi APBD untuk AMPL melalui refocusing program tahunan, Menggalang kerjasama pendanaan dengan dunia usaha untuk investasi AMPL diperkotaan. 
Proses Pemberdayaan Pemerintah Kabupaten Simeulue Dalam Memenuhi Kebutuhan Dasar Manusia Dalam Peningkatan Drajat Kesehatan Masyarakat dalam Bidang Air Bersih

Pembagian luas wilayah kabupaten kecamatan, jumlah desa dan dusun, nama ibu kota kecamatan dan jarak ibu kota kecamatan dengan ibu kota Kabupaten Simeulue dapat dilihat dalam tabel 2. (5.1) dibawah ini :

Tabel 2.

Pembagian dan Luas Wilayah Kabupaten Simeulue

\begin{tabular}{|c|l|c|c|c|l|c|}
\hline No. & Nama Kecamatan & $\begin{array}{c}\text { Jumlah } \\
\text { Desa }\end{array}$ & $\begin{array}{c}\text { Jumlah } \\
\text { Dusun }\end{array}$ & $\begin{array}{c}\text { Luas Wilayah } \\
\text { (Ha) }\end{array}$ & Ibu Kota & $\begin{array}{c}\text { Jarak ke } \\
\text { Ibu Kota } \\
\text { Kabupaten } \\
\text { (Km) }\end{array}$ \\
\hline $\mathbf{1}$ & \multicolumn{1}{|c|}{$\mathbf{2}$} & $\mathbf{3}$ & $\mathbf{4}$ & $\mathbf{5}$ & $\mathbf{6}$ & $\mathbf{7}$ \\
\hline 1 & Teupah Selatan & 19 & 55 & 222,24 & Labuhan Bajau & 46,00 \\
\hline 2 & SimeulueTimur & 17 & 48 & 175,97 & Sinabang & 0,00 \\
\hline 3 & Teupah Barat & 18 & 52 & 146,73 & Salur & 24,00 \\
\hline 4 & Teupah Tengah & 12 & 35 & 83,69 & Lasikin & 11,00 \\
\hline 5 & Simeulue Tengah & 16 & 46 & 112,48 & Kampung Aie & 64,00 \\
\hline 6 & Teluk Dalam & 10 & 26 & 224,68 & Kuala Bakti & 57,00 \\
\hline 7 & Simeulue Cut & 8 & 29 & 35,40 & Kuta Padang & 68,00 \\
\hline 8 & Salang & 16 & 44 & 198,96 & Nasreuhe & 70,00 \\
\hline 9 & Simeulue Barat & 14 & 48 & 446,07 & Sibigo & 93,00 \\
\hline 10 & Alafan & 8 & 28 & 191,87 & Langi & 135,00 \\
\hline & \multicolumn{1}{|c|}{ Jumlah } & $\mathbf{1 3 8}$ & $\mathbf{4 1 1}$ & $\mathbf{1 . 8 3 8 , 0 9}$ & & \\
\hline
\end{tabular}

Sumber : BPS - Kabupaten Simeulue dalam Angka Tahun 2017

Proyeksi Jumlah penduduk Kabupaten Simeulue pada tahun 2021 adalah 94.192 Jiwa, sebagaimana dapat dilihat pada tabel 3 .

Tabel 3.

Jumlah Penduduk Tahun 2015 dan Proyeksi

Tahun 2016 - 2021 Kabupaten Simeulue

\begin{tabular}{|c|l|r|r|r|r|r|r|r|}
\hline \multirow{2}{*}{ No. } & \multirow{2}{*}{ KECAMATAN } & $\begin{array}{c}\text { Jumlah } \\
\text { Penduduk } \\
\text { (jiwa) }\end{array}$ & \multicolumn{6}{|c|}{$\begin{array}{c}\text { PROYEKSI LAJU PERTUMBUHAN PENDUDUK } \\
\text { Angka Tingkat Pertumbuhan Penduduk = 1,105\% } \\
\text { (jiwa) }\end{array}$} \\
\cline { 3 - 9 } & & $\mathbf{2 0 1 5}$ & $\mathbf{2 0 1 6}$ & $\mathbf{2 0 1 7}$ & $\mathbf{2 0 1 8}$ & $\mathbf{2 0 1 9}$ & \multicolumn{1}{c|}{$\mathbf{2 0 2 0}$} & $\mathbf{2 0 2 1}$ \\
\hline $\mathbf{1}$ & Teupah Selatan & 8.615 & 8.710 & 8.805 & 8.901 & 8.996 & 9.091 & 9.186 \\
\hline $\mathbf{2}$ & Simeulue Timur & 26.785 & 27.081 & 27.377 & 27.673 & 27.969 & 28.265 & 28.561 \\
\hline $\mathbf{3}$ & Teupah Barat & 7.976 & 8.064 & 8.152 & 8.240 & 8.329 & 8.417 & 8.505 \\
\hline $\mathbf{4}$ & Teupah Tengah & 5.969 & 6.035 & 6.101 & 6.167 & 6.233 & 6.299 & 6.365 \\
\hline $\mathbf{5}$ & Simeulue Tengah & 6.963 & 7.040 & 7.117 & 7.194 & 7.271 & 7.348 & 7.425 \\
\hline $\mathbf{6}$ & Teluk Dalam & 5.483 & 5.544 & 5.604 & 5.665 & 5.725 & 5.786 & 5.847 \\
\hline $\mathbf{7}$ & Simeulue Cut & 3.019 & 3.052 & 3.086 & 3.119 & 3.152 & 3.186 & 3.219 \\
\hline $\mathbf{8}$ & Salang & 8.519 & 8.613 & 8.707 & 8.801 & 8.896 & 8.990 & 9.084 \\
\hline $\mathbf{9}$ & Simeulue Barat & 10.538 & 10.654 & 10.771 & 10.887 & 11.004 & 11.120 & 11.237 \\
\hline $\mathbf{1 0}$ & Alafan & 4.468 & 4.517 & 4.567 & 4.616 & 4.665 & 4.715 & 4.764 \\
\hline & Simeulue & $\mathbf{8 8 . 3 3 5}$ & $\mathbf{8 9 . 3 1 1}$ & $\mathbf{9 0 . 2 8 7}$ & $\mathbf{9 1 . 2 6 3}$ & $\mathbf{9 2 . 2 3 9}$ & $\mathbf{9 3 . 2 1 6}$ & $\mathbf{9 4 . 1 9 2}$ \\
\hline
\end{tabular}


Berdasarkan rincian tabel diatas Jumlah Penduduk Kabupaten Simeulue Sampai akhir tahun 2021, distribusi penduduk terbesar terdapat di Kecamatan Simeulue Timur dengan jumlah 28.561 jiwa $(30,32 \%)$ total penduduk Kabupaten Simeulue dan kecamatan lainnya tersebar secara merata dengan Kecamatan Simeulue Cut berpenduduk terkecil yaitu 3.219 jiwa $(3,42 \%)$ Sedangkan proyeksi jumlah penduduk tahun 2021 sebesar 94.192 Jiwa.

\section{Air Minum}

Dalam Tujuan Pembangunan Milenium, definisi operasional akses air minum layak adalah yang menggunakan sumber air minum layak seperti sambungan air minum rumah tangga, lubang bor, sumur gali yang terlindungi, mata air terlindung, tampungan air hujan. Sedangkan definisi operasional akses sanitasi layak adalah yang menggunakan sanitasi dasar seperti toilet guyur/toilet siram guyur atau jamban, pipa saluran pembuangan, tangki septic atau jamban lubang, jamban cemplung dengan ventilasi yang baik, jamban cemplung dengan segel slab atau toilet/jamban kompos.

Akses aman terhadap air minum terdiri dari Jaringan Perpipaan dan Bukan Jaringan Perpipaan (BJP). Sistem Penyediaan Air Minum (SPAM) Bukan Jaringan Perpipaan adalah sebagaimana diatur dalam Peraturan Pemerintah Nomor : 122 Tahun 2015 Tentang Sistem Penyediaan Air Minum. Jenis SPAM meliputi SPAM Jaringan Perpipaan dan SPAM Bukan Jaringan Perpipaan.

SPAM Jaringan Perpipaan meliputi : Unit Air Baku, Unit Produksi, Unit DistribusiUnit Pelayanan.

SPAM Jaringan Bukan Perpipaan meliputi : Sumur Dangkal, Sumur Pompa, Bak Penampungan Air Hujan, Terminal Air, Bangunan Penangkap Mata Air.

Status capaian kinerja pelayanan air minum Kabupaten Simeulue dengan menggunakan indikator target universal akses tersebut pada tahun 2016 adalah sebesar 51.08 $\%$ rumah tangga telah memiliki akses berkelanjutan terhadap sumber air minum layak diperdesaan, dan untuk daerah perkotaan sebesar 53.08 \% rumah tangga telah memiliki akses berkelanjutan terhadap sumber air minum layak.

\section{Perdesaan}

Tabel 4.

Perkembangan Kinerja Air Minum Kabupaten Simeulue Tahun 2017

\begin{tabular}{|r|l|r|r|r|r|}
\hline No & Kecamatan & $\begin{array}{c}\text { Jumlah Penduduk } \\
\text { Jiwa }\end{array}$ & Jumlah KK & $\begin{array}{c}\text { Jumlah Akses } \\
\text { Terhadap Air } \\
\text { Minum/Jiwa }\end{array}$ & $\begin{array}{c}\text { Persentase } \\
\text { Air Minum } \\
\text { (\%) }\end{array}$ \\
\hline 1 & Teupah Selatan & 8,882 & 2,231 & 1,354 & 15.24 \\
\hline 2 & Simeulue Timur & 1,052 & 938 & 708 & 67.30 \\
\hline 3 & Teupah Barat & 7,633 & 1,945 & 4,399 & 57.63 \\
\hline 4 & Teupah Tengah & 5,722 & 1,529 & 3,758 & 65.68 \\
\hline 5 & Simeulue Tengah & 4,808 & 1,217 & 2,166 & 45.05 \\
\hline 6 & Teluk Dalam & 5,421 & 1,262 & 4,123 & 76.06 \\
\hline 7 & Simeulue Cut & 3,162 & 768 & 3,162 & 100.00 \\
\hline 8 & Salang & 8,545 & 1,916 & 7,653 & 89.56 \\
\hline 9 & Simeulue Barat & 5,602 & 1,266 & 832 & 14.85 \\
\hline 10 & Alafan & 4,711 & 942 & 214 & 4.54 \\
\hline & Jumlah & $\mathbf{5 5 , 5 3 8}$ & $\mathbf{1 4 , 0 1 4}$ & $\mathbf{2 8 , 3 6 9}$ & $\mathbf{5 1 . 0 8}$ \\
\hline
\end{tabular}

Sumber : BPS dan Dinas Kesehatan Kab. Simeulue 2017 
a. Perkotaan

Tabel 5.

Perkembangan Kinerja Air Minum Kabupaten Simeulue Tahun 2017

\begin{tabular}{|c|l|c|r|r|r|}
\hline No & Kecamatan & $\begin{array}{c}\text { Jumlah Penduduk } \\
\text { Jiwa }\end{array}$ & Jumlah KK & $\begin{array}{c}\text { Jumlah Akses } \\
\text { Terhadap Air } \\
\text { Minum/liwa }\end{array}$ & $\begin{array}{c}\text { Persentase } \\
\text { Air Minum } \\
\text { (\%) }\end{array}$ \\
\hline 1 & SimeulueTimur & 18,088 & 4,307 & 10,331 & 57.12 \\
\hline 2 & Simeulue Tengah & 2,174 & 545 & 990 & 45.54 \\
\hline 3 & Simeulue Barat & 1,515 & 377 & 320 & 21.12 \\
\hline \multicolumn{2}{|r|}{ Jumlah } & $\mathbf{2 1 , 7 7 7}$ & $\mathbf{5 , 2 2 9}$ & $\mathbf{1 1 , 6 4 1}$ & $\mathbf{5 3 . 4 6}$ \\
\hline
\end{tabular}

Sumber : BPS dan Dinas Kesehatan Kab. Simeulue 2017

Ditinjau dari sistem penyediaan air minum, perkembangan instalasi pengolahan air minum Kabupaten Simeulue ditampilkan dalam Tabel 2.6, 2.7 dan 2.8 berikut ini :

Tabel 6.

Perkembangan Instalasi Pengolahan Air Minum

\begin{tabular}{|l|l|l|c|c|c|c|}
\hline No & Nama IPA & $\begin{array}{c}\text { Kapasitas } \\
\text { Terpasang } \\
\text { (liter/detik) }\end{array}$ & $\begin{array}{c}\text { Kapasitas } \\
\text { Produksi } \\
\text { (liter/detik) }\end{array}$ & $\begin{array}{c}\text { Volume } \\
\text { Reservoir } \\
(\mathbf{m 3})\end{array}$ & Type IPA & $\begin{array}{c}\text { Tahun } \\
\text { Dibangun }\end{array}$ \\
\hline $\mathbf{1}$ & Labuah & 10 & 10 & 320 & Konvensional & 1986 \\
\hline $\mathbf{3}$ & Sefoyan & 40 & 40 & 1300 & Paket & 2003 \\
\hline $\mathbf{4}$ & Kolok & 10 & 10 & 150 & Paket & 2012 \\
\hline $\mathbf{5}$ & Sibigo & 10 & 10 & 450 & Paket & 2002 \\
\hline $\mathbf{6}$ & Salur Latun & 10 & 10 & 450 & Paket & 2013 \\
\hline $\mathbf{7}$ & Kap. Aie & 10 & 10 & 200 & Paket & 2014 \\
\hline $\mathbf{8}$ & Sinar Bahagia & 10 & 10 & 200 & Paket & 2015 \\
\hline & Total & $\mathbf{1 0 0}$ & $\mathbf{1 0 0}$ & $\mathbf{3 0 2 0}$ & & \\
\hline
\end{tabular}

Sumber : PDAM Tirta Fulawan Kabupaten Simeulue 2016.

Tabel 7.

Distribution Centre (booster)

\begin{tabular}{|c|l|c|c|c|}
\hline No & Nama Booster & $\begin{array}{c}\text { Kapasitas Pompa } \\
\text { (liter/detik) }\end{array}$ & $\begin{array}{c}\text { Volume } \\
\text { Reservoir (m3) }\end{array}$ & Tahun Dibangun \\
\hline $\mathbf{1}$ & Labuah & 10 & 320 & 1986 \\
\hline $\mathbf{2}$ & IKK Sibigo & 10 & 450 & 2002,2006 \\
\hline $\mathbf{3}$ & Sefoyan & $50(15,15,20)$ & 1.300 & 2003 \\
\hline $\mathbf{4}$ & Suplesi (K. Makmur) & $50(20,30)$ & & 2012,2013 \\
\hline $\mathbf{5}$ & Kolok & $40(20,20)$ & 150 & 2012 \\
\hline $\mathbf{6}$ & Salur Latun & 20 & 450 & 2013 \\
\hline
\end{tabular}




\begin{tabular}{|c|l|c|c|c|}
\hline $\mathbf{7}$ & Kap. Aie & 20 & 200 & 2014 \\
\hline $\mathbf{8}$ & Sinar Bahagia & 20 & 200 & 2015 \\
\hline & Total & 220 & 3.070 & 2015 \\
\hline
\end{tabular}

Sumber : PDAM Tirta Fulawan Kabupaten Simeulue 2016.

Tabel 8.

Data Pelayanan Per Kecamatan

\begin{tabular}{|lcccccc|}
\hline Nama Kecamatan & $\begin{array}{c}\text { Kapasitas } \\
\text { Terpasang }\end{array}$ & $\begin{array}{c}\text { Kapasitas } \\
\text { Produksi }\end{array}$ & $\begin{array}{c}\text { Tahun Di } \\
\text { Bangun }\end{array}$ & $\begin{array}{c}\text { Jumlah } \\
\text { SR }\end{array}$ & $\begin{array}{c}\text { SR } \\
\text { Aktif }\end{array}$ & Ket. \\
\hline Simaulue Timur & $60 \mathrm{~L} / \mathrm{dt}$. & $60 \mathrm{~L} / \mathrm{dt}$. & - & 3.482 & 2.641 & \\
\hline Simeulue Barat & $20 \mathrm{~L} / \mathrm{dt}$. & $10 \mathrm{~L} / \mathrm{dt}$. & 2002,2015 & 600 & 200 & \\
\hline Simeulue Tengah & $10 \mathrm{~L} / \mathrm{dt}$. & - & 2014 & 320 & - & $\begin{array}{c}\text { SR Terpasang } \\
2016\end{array}$ \\
\hline Teupah Barat & $10 \mathrm{~L} / \mathrm{dt}$. & - & 2013 & 416 & - & $\begin{array}{c}\text { SR Terpasang } \\
2016\end{array}$ \\
\hline
\end{tabular}

Sumber : PDAM Tirta Fulawan Kabupaten Simeulue 2016

1. Peran Pemerintah Dalam Menyelenggarakan Sistem Fisik (Teknik) dan Non Fisik (Kelembagaan, Manajemen, Keuangan, Peran Masyarakat dan Hukum) Dalam Kesatuan yang Utuh Trintegrasi Prasarana Sanitasi Di Kabupaten Simeulue.

a. Sanitasi

Status capaian kinerja pelayanan sanitasi Kabupaten Simeulue tahun 2016 adalah sebesar $31.86 \%$ rumah tangga telah memiliki akses berkelanjutan terhadap sanitasi layak dan $57.31 \%$ rumah tangga telah memiliki akses berkelanjutan terhadap sanitasi layak sehat permanen.

Ditinjau dari sistem penyediaan sanitasi, capaian kinerja pelayanan sanitasi Kabupaten Simeulue ditampilkan dalam tabel 2.10 dan 2.11 berikut ini:

\section{a. Perdesaan}

Tabel 9.

Jumlah Rumah Tangga Menurut Jenis Sarana Sanitasi Tahun 2017 


\begin{tabular}{|r|l|c|r|r|r|}
\hline No & Kecamatan & $\begin{array}{c}\text { Jumlah } \\
\text { Penduduk }\end{array}$ & Jumlah KK & $\begin{array}{c}\text { Jumlah Akses } \\
\text { Terhadap } \\
\text { Jamban/liwa }\end{array}$ & $\begin{array}{c}\text { Persentase } \\
\text { Jamban (\%) }\end{array}$ \\
\hline 1 & Teupah Selatan & 8,882 & 2,231 & 879 & 9.90 \\
\hline 2 & SimeulueTimur & 1,052 & 938 & 1,905 & 181.08 \\
\hline 3 & Teupah Barat & 7,633 & 1,945 & 4,536 & 59.43 \\
\hline 4 & Teupah Tengah & 5,722 & 1,529 & 2,982 & 52.11 \\
\hline 5 & Simeulue Tengah & 4,808 & 1,217 & 1,025 & 21.32 \\
\hline 6 & Teluk Dalam & 5,421 & 1,262 & 1,261 & 23.26 \\
\hline 7 & Simeulue Cut & 3,162 & 768 & 1,937 & 61.26 \\
\hline 8 & Salang & 8,545 & 1,916 & 1,162 & 13.60 \\
\hline 9 & Simeulue Barat & 5,602 & 1,266 & 1,319 & 23.55 \\
\hline 10 & Alafan & 4,711 & 942 & 691 & 14.67 \\
\hline & Jumlah & $\mathbf{5 5 , 5 3 8}$ & $\mathbf{1 4 , 0 1 4}$ & $\mathbf{1 7 , 6 9 7}$ & $\mathbf{3 1 . 8 6}$ \\
\hline
\end{tabular}

Sumber : BPS dan Dinas Kesehatan Kab. Simeulue 2017

\section{b. Perkotaan}

Tabel 10.

Jumlah Rumah Tangga Menurut Jenis Sarana Sanitasi Tahun 2017

\begin{tabular}{|r|l|r|r|r|r|}
\hline No & Kecamatan & $\begin{array}{c}\text { Jumlah } \\
\text { Penduduk } \\
\text { Jiwa }\end{array}$ & Jumlah KK & $\begin{array}{c}\text { Jumlah Akses } \\
\text { Terhadap } \\
\text { Jamban }\end{array}$ & $\begin{array}{c}\text { Persentase } \\
\text { Jamban Sehat } \\
\text { (\%) }\end{array}$ \\
\hline 1 & Simeulue Timur & 18,088 & 4,307 & 11,037 & 61.02 \\
\hline 2 & Simeulue Tengah & 2,174 & 545 & 642 & 29.53 \\
\hline 3 & Simeulue Barat & 1,515 & 377 & 801 & 52.87 \\
\hline \multicolumn{2}{|c|}{ Jumlah } & $\mathbf{2 1 , 7 7 7}$ & $\mathbf{5 , 2 2 9}$ & $\mathbf{1 2 , 4 8 0}$ & $\mathbf{5 7 . 3 1}$ \\
\hline
\end{tabular}

Sumber: BPS dan Dinas Kesehatan Kab. Simeulue 2016

Pada indikator akses air minum dan sanitasi layak, dibandingkan dengan capaian Provinsi Aceh pada tahun 2016, status target capaian kinerja pelayanan air minum tingkat Provinsi sebesar $71 \%$ dan sanitasi sebesar 65\%, sedangkan Kabupaten Simeulue masih dibawah rata-rata Provinsi.

\section{SIMPULAN}

Dengan melihat permasalahan diatas maka peneliti mendapatkan kesimpulan antara lain Peran Pemerintah Kabupaten Simeulue dalam pemberdayaan air bersih dan sanitasi guna mendorong pengembangan kapasitas daerah serta penyediaan pelayanan air minum dan penyehatan lingkungan untuk memenuhi target Universal Acces 100\% Mdgs program tingkat nasional di kabupaten Simeulue aceh. Di ditargetkan tercapai di Tahun 2021 Sesuai dengan RAD AMPL 2017-2017 dapat dijadikan sebagai salah satu pemacu dan semangat untuk dapat melakukan upaya yang lebih baik dalam mensejahterakan masyarakat. Penanggulangan permasalahan air minum dan penyehatan lingkungan bukanlah masalah yang harus diselesaikan oleh Pemerintah Kabupaten Simeulue saja, namun oleh seluruh masyarakat Kabupaten Simeulue termasuk masyarakat yang menjadi sasaran.

Proses pemberdayaan pemerintah untuk memenuhi kebutuhan dasar Koordinasi diantara stakeholders maupun instansi sangat perlu dioptimalkan, terutama dalam hal penentuan target dan sasaran program kegiatan Pembedayaan air bersih secara berjenjang dari tingkat Kabupaten, Kecamatan, Kelurahan/Lembaga sampai ketingkat kelompok sasaran. Hal ini 
dilakukan melalui mekanisme Musrenbang dalam siklus perencanaan dan penganggaran tahunan daerah. Pemerintah Kabupaten Simeulue mendukung dan melaksanakan upaya pembangunan PDAM dan sanitasi untuk air bersih bagi masyarakat perdesaan dan perkotaan. Komitmen tersebut telah tertuang di dalam dokumen-dokumen perencanaan baik jangka panjang, menengah maupun tahunan, dengan melaksanakan berbagai program dan kegiatan serta berbagai sumber dan melalui strategi penanganan langsung maupun tidak langsung.

Adapun peran dalam menyelanggarakan hal tersebut perlu adanya proses penyadaran terkait dengan sosioal kultural masyarakat, upaya pengembangan kapasitas air bersih dalam yang dalam hal ini PDAM atau sanitasi lainnya. Peran Pemerintah tidak akan berhasil apa bila tidak diimbangi dengan program penyadaran masyarakat (public awareness) yaitu sebuah upaya untuk mengurangi atau bahkan menghapuskan mental dan budaya miskin dengan jalan mengingatkan, meyakinkan dan memberikan semangat kepada masyarakat agar berusaha untuk bangkit dari kemiskinan dengan melakukan kerja keras dan membiasakan diri untuk malu menerima bantuan sebagai orang miskin. Selanjutnya pemerintah daerah perlu juga menciptakan tata pemerintahan yang baik (good governaance) dan (Good Cooporate governance) dalam hal pemberdayaan perusahaan daerah (swasta). Yaitu sebuah tata pemerintahan yang mengedepankan hubungan sinergi antara elemen-elemen pemerintah, swasta Dan masyarakat sipil dengan melibatkan masyarakat itu sendiri berdasarkan prinsip-prinsip partisipasi, akuntabilitas, transparansi, dan pada pengutamaan kepentingan masyarakat. Percepatan Pencapaian pemberdayaan air bersih RAD AMPL ini memerlukan dukungan dan peranserta seluruh pelaku pembangunan dari kalangan pemerintah, DPRD, perguruan tinggi, organisasi dan lembaga swadaya masyarakat, swasta dan lembaga internasional. Keterlibatan dan dukungan ini diharapkan terus berlanjut sampai pada pelaksanaan RAD AMPL dan evaluasi pencapaian hasil RAD AMPL.

\section{REFERENSI}

Afrizal (2003). Partisipasi Publik dalam Penyusunan Undang-undang: Studi Kasus RUU Yayasan dan RUU Penyiaran. Universitas Indonesia: Jakarta.

Bungin, Burhan, 2007. Penelitian Kualitatif. Kencana Prenada Media Group. Jakarta.

Graham, Katherine A. and Susan D. Philips, (eds) (1998). Citizen Engagment: Lesson In Participation From Local Government. The Institute of Public Administration on Canada, Toronto, Ontario, Canada.

Lester, James P. dan Joseph Stewart, JR (2000). Public Policy: An Evolutionary Approach. Wadsworth/Thomas Learning, Belmont, USA.

Mardikanto, T., P. Soebianto, 2012. Pemberdayaan Masyarakat dalam Perspektif Kebijakan Publik. Alfabeta. Bandung

Moleong, J. Lexi, 2013. Metodologi Penelitian Kualitatif Edisi Revisi. Remaja Rosda Karya Bandung.

Siagian. P., Sondang, 2014. Administrasi Pembangunan Konsep, Dimensi, dan Strategi. Bumi Aksara. Jakarta.

Singarimbun, Masri (1995). Metode Penelitian Survei. LP3S, Jakarta. 
Suryadi, Suhardi dan Julmansyah (2001). Partisipasi Politik Masyarakat dalam Pengembangan Demokrasi: Kasus Legislasi Peraturan Daerah tentang Badan Perwakilan Desa di Kabupaten Sumbawa. LP3ES, Konsepsi, dan Pustaka Pelajar.

Thoha, Miftah (1992). Dimensi-dimensi Prima Ilmu Administrasi Negara. Jakarta: PT. Raja Grafindo Persada.

Turner, Mark and David Hulme. Governance, Administration and Development: Making the State Work. MaCMillan Press Ltd, London, 1997.

Undang Dasar Negara Republik Indonesia Tahun 1945;

Undang-Undang Nomor 7 Tahun 2004 tentang Sumber Daya Air;

Undang-Undang Nomor 33 Tahun 2004 tentang Perimbangan Keuangan antara Pemerintah Pusat dan Pemerintahan Daerah;

Peraturan Pemerintah Nomor 16 Tahun 2005 tentang Pengembangan Sistem Penyediaan Air Minum;

Peraturan Pemerintah Nomor 6 Tahun 2006 tentang Pengelolaan Barang Milik Negara;

Peraturan Pemerintah Nomor 38 Tahun 2007 tentang Pembagian Urusan Pemerintahan Antara Pemerintah, Pemerintahan Daerah Provinsi, danPemerintahan Daerah Kabupaten/Kota;

Peraturan Pemerintah No. 50 Tahun 2007 tentang Tata Cara Pelaksanaan Kerja Sama Daerah;

Peraturan Pemerintah Nomor. 26 Tahun 2008 tentang Rencana Tata Ruang Wilayah Nasional;

Peraturan Pemerintah Nomor 42 Tahun 2008 tentang Pengelolaan Sumber Daya Air;

Peraturan Pemerintah Nomor 45 Tahun 2008 tentang Pedoman Pemberian Insentif dan Pemberian Kemudahan Penanaman Modal di Daerah;

Peraturan Presiden No. 29 Tahun 2009 tentang Pemberian Jaminan dan Subsidi Bunga oleh Pemerintah Pusat dalam rangka Percepatan Penyediaan Air Minum ;

Peraturan Presiden Republik Indonesia Nomor 9 Tahun 2005 tentang Kedudukan, Tugas, Fungsi, Susunan Organisasi dan Tata Kerja Kementerian Negara Republik Indonesia sebagaimana telah diubah dengan Peraturan Presiden Republik Indonesia Nomor 62 Tahun 2005;

Peraturan Presiden Republik Indonesia Nomor 5 Tahun 2010 tentang Rencana Pembangunan Jangka Menengah Nasional 2010-2014;

Peraturan Presiden No. 29 Tahun 2009 tentang Pemberian Jaminan dan Subsidi Bunga oleh Pemerintah Pusat dalam rangka Percepatan Penyediaan Air Minum;

Peraturan Menteri Pekerjaan Umum Nomor 02/PRT/M/2010 tentang Rencana Strategis Kementerian Pekerjaan Umum Tahun 2010-2014; 